\title{
ELDERLY MIGRATION INTO RAPIDLY GROWING AREAS: A TIME SERIES APPROACH
}

\author{
Stanley K. Smith and Henry H. Fishkind*
}

\begin{abstract}
Many studies have dealt with the determinants of elderly migration, but none have done so from a time series perspective. This article focuses on the timing of elderly migration, or the factors that cause migration levels to be higher some years than other years. A model is developed for net migration of the elderly into rapidly growing areas. It is tested using data for three rapidly growing states: Florida, Arizona and Nevada. The model is found to explain a large proportion of the variation in annual levels of elderly net migration into these states and to provide estimates that track very well both inside and outside the sample period. The potential usefulness of the model in forecasting elderly and total population appears to be substantial.
\end{abstract}

\section{Introduction}

The elderly population of the United States is growing rapidly. Between 1970 and 1980 , the number of persons age 65 and above increased by 27 percent, compared to an 11 percent increase for the population as a whole. In seven states, the elderly population increased by more than one-half; in 19 states, by more than one-third. In many local areas, growth rates were even higher. In Florida, for example, the population age 65 and above more than doubled in 18 of the state's 67 counties. Even in states in which overall population growth is slow, frequently there are local areas in which the number of older persons is growing rapidly.

In many states and local areas, however, annual growth rates of the elderly population are very volatile. There are some years in which growth rates are high and others in which they are low. The cause of this volatility is migration. During some years, many older persons

\footnotetext{
*Associate Professor of Economics and Population Program Director, Bureau of Economic and Business Research, University of Florida; and President, M. G. Lewis Econometrics, Winter Park, Florida.
}

move into rapidly growing areas; during other years, relatively few move in. Were it not for migration, the elderly populations of states and local areas would grow at steady, slowly. changing rates, determined by age structures and mortality rates. Migration is the primary cause of year-to-year fluctuations in the growth rates of elderly populations of states and local areas.

Why do levels of elderly migration fluctuate from year to year? A large amount of literature has been published in recent years dealing with the determinants of migration among older persons (e.g. Manley, 1954; Lenzer, 1965; Goldscheider, 1966; Goldstein, 1967; Bultena and Wood, 1969; Barsby and Cox, 1975; Serow, 1978; Chevan and Fisher, 1979; Long and Hansen, 1979; Biggar, 1980; Flynn, 1980). All these studies were cross-sectional in nature, focusing on migration over a particular period of time. They dealt primarily with the characteristics of migrants and non-migrants, the origins and destinations of migrants and the reasons people move. None of these studies considered the timing of migration, or the causes of year-to-year fluctuations in the number of older persons who migrate.

We believe a study of the timing of elderly migration can be very useful. One out of nine residents of the United States is age 65 and above; for many state and local areas this proportion is much higher. The size of the elderly population has a major impact on many aspects of community life: the demand for health, education and recreation services; employment and labor force participation rates; tax revenues and public expenditures; and more. Accurate forecasts of the elderly population are, therefore, critical for many types of planning, in both the public and private sectors. Besides adding to our understanding of the determinants of migration, a study of the timing of elderly migration will provide a basis for improving the accuracy of short-run forecasts of the number of older persons. As the elderly population becomes larger-both in number and as a proportion of total population-such forecasts become increasingly important. 
The model developed in this article focuses on the effects of several economic variables on the timing of elderly migration. This focus is not meant to imply that economic factors are the only (or even primary) ones that affect elderly migration. Climate, health, place of birth, the location of friends and relatives and socioeconomic status are all important determinants of elderly migration. The present article, however, does not seek to explain why some older people move while others do not, or why the elderly tend to move into some areas and not into others. Rather, this article deals with year-toyear fluctuations in a given migration stream. It focuses on deviations from trends, not on the determinants of the underlying trends themselves. Consequently, the explanatory variables are ones that primarily affect decisions regarding when to move, not decisions regarding whether or where to move.

The primary objective of this study is to determine whether flows of elderly migrants into rapidly growing areas tend to fluctuate over time; and if so, whether a model can be developed to explain and forecast these fluctuations. In the second section, we develop a model of the timing of elderly migration into rapidly growing areas and describe the explanatory variables used in that model. In the third section, we describe the data and techniques used to construct annual measures of elderly migration. In the fourth section, we report on the model's performance in explaining and forecasting net migration of the elderly into three states with rapidly increasing numbers of older persons. In the fifth section, we discuss our results and draw some conclusions.

\section{Model of Elderly Migration}

Studies of migration are often grounded in the economic theory of consumer behavior. Some studies are couched explicitly in terms of utility-maximization (e.g. Levy and Wadycki, 1972; Kau and Sirmans, 1977; Graves and Linneman, 1979). Others focus on individual perceptions of discounted costs and benefits (e.g. Sjaastad, 1962; Bowles, 1970; Fields, 1976). While these studies differ in their specific areas of emphasis, they are similar in the common underlying assumption that migration is a rational response to the existence of regional differences in lifetime real income and/or quality of life.

The model presented here is based on the same theoretical foundation. Individuals are assumed to maximize lifetime utility, derived from the consumption of goods, services and leisure, subject to time and income constraints. Within this framework, decisions to move or stay depend on evaluations of the maximum lifetime utility available at all potential locations. Lifetime utility is determined by lifetime real income and personal evaluations of such factors as access to goods and services, climate, topography and proximity to friends and relatives. If a person determines that a higher level of total lifetime utility can be obtained at location $j$ than at present location $i$ and all other possible locations (net of moving costs), that person will move from location i to location $\mathrm{j}$.

While the economic theory of consumer behavior is derived from maxims of individual decision-making, the present study focuses on aggregate behavior. It deals not with individual uni-directional moves, but with the net flow of elderly migrants into or out of an area. Since net migration is the summation of the moves of all individual movers, however, factors that affect individual migration decisions also affect net migration flows. The problem is to identify the aggregate economic variables that affect the timing of individual migration behavior, hence aggregate migration flows. The theory of consumer behavior helps identify these variables.

Individual migration decisions are determined by perceptions of the real income and quality of life available in all possible locations. Variables that alter real income and quality of life therefore affect the timing of migration. In this article, we consider only the effects of changes in real income. Although some qualityof-life variables change over time (e.g. crime rates, levels of pollution and congestion), they generally do not fluctuate significantly from year to year, and are not likely to have changed much for the states and time period covered by this study. In addition, some important quality-of-life variables do not change over time (e.g. location, climate).

The present study focuses on the timing of elderly migration into areas in which the number of older persons is growing rapidly. For purposes of exposition, these are called "attractive" areas. An area is made relatively attractive or unattractive by such factors as climate, topography, cost of living and the availability of particular goods and services. One way in which an area can be judged to be 
attractive or unattractive to older persons is to look at the net flow of elderly migrants over time. If persistently more older persons move into an area than move out, it can be called an attractive area. If persistently more older persons move out than move in, it can be called an unattractive area. In our use of the term, "attractiveness" is determined solely by the net flow of older persons. It is not affected by an evaluation of the relative merits of various areas.

Increases in real income are expected to promote net migration of the elderly into attractive areas for two reasons. People can more easily bear the costs of an interstate move when real income rises than when it falls. More important, attractive living conditions are normal goods (e.g. Cebula and Vedder, 1973; Graves, 1979). The consumption of normal goods rises when real income rises. But attractive living conditions are location-specific; they cannot be moved. People can increase their consumption of location-specific goods only by moving into (or visiting) the areas in which those goods are present. Increases in real income, therefore, promote greater consumption of attractive living conditions, causing increases in net migration of the elderly into attractive areas.

What economic factors affect the real incomes of older persons? Previous time series studies of total migration have focused on labor force variables such as wages and unemployment rates (e.g. Bell, 1967; Wilkinson, 1970; Crow, 1973, Salvatore, 1977; Milne, 1981; Plaut, 1981). These studies, however, dealt with movements of the entire population rather than with the elderly population. Since the vast majority of older persons are not in the labor force, labor force variables are not likely to affect the migration behavior of older persons. ${ }^{1}$ Other explanatory variables must be considered. We suggest the following model of net migration of the elderly:

\section{1) $\mathrm{MIG}=\mathrm{f}$ (INFL, HOUSE)}

The rate of inflation (INFL) has a strong impact on the real incomes of older persons. A substantial proportion of the income of older persons is relatively fixed by non-indexed retirement benefits and wealth held in fixed value forms (e.g. bonds, savings accounts). The buying power of fixed income is subject to rapid erosion during periods of rapid inflation. Older persons are more openly exposed to infla- tion than others because they have few debts and hold relatively high proportions of assets in fixed-value forms (Bach and Stephenson, 1974, p. 5). In this study, the rate of inflation is measured by the implicit price deflator for consumer expenditures (base $=1972$ ). Increases in the rate of inflation are expected to have a negative effect on net migration of the elderly into attractive areas.

Approximately two-thirds of the elderly own their own homes. For many older persons, equity in a home accounts for a large proportion of net worth (Wentworth and Motley, 1970, p. 69; Sherman, 1973, p. 13). The condition of the housing market thus has a major impact on the economic position of older persons. Two types of effects operate-one relating to wealth and the other to liquidity. When housing markets are strong, prices rise and the wealth (i.e. lifetime real income) of homeowners increases. A positive income effect leads to greater migration into attractive areas. In addition, when markets are strong, potential migrants can sell their homes relatively easily and transfer their wealth from one form (a house in the area of origin) to another (a house, condominium or mobile home in the area of destination, perhaps). When markets are weak, potential migrants find it difficult to sell their homes at an acceptable price. They are likely to delay a move until some later time when the market has improved. The condition of the housing market thus affects the timing of migration of the elderly by altering lifetime real income and by affecting the ease with which assets can be transformed from one form into another. Annual sales of existing singlefamily housing units (HOUSE) is used as a proxy for the housing market. It is expected to have a positive effect on net migration of the elderly into attractive areas.

Several other variables were considered in the early stages of the empirical analysis. Social security payments and asset income are two of the primary sources of income of older persons. Of all households headed by older persons, approximately 90 percent receive social security income and 50 percent receive asset income (Fox, 1973, p. 20; Social Security Administration, 1980 , p. 19-23). Social security payments per capita (real) and the summation of all interest, dividends and rent payments were used as measures of these two sources of income for older persons. Both these variables were found to have small, insignificant effects 
on net migration of the elderly and to introduce a high degree of multicollinearity into the estimating equations. For these reasons, both were deleted from the empirical analysis. ${ }^{2}$

A number of factors not considered in this study also affect the timing of individual migration decisions: retirement, changes in health status, death of a spouse, and so forth. While these factors undoubtedly have significant effects for specific individuals, they will not generally affect the timing of aggregate migration flows because for the elderly population as a whole, these retirement, health and mortality characteristics either remain stable over time or follow a steady trend. They do not fluctuate a great deal from year to year. Only if such factors were to change abruptly for a large proportion of the population (e.g. a change in the mandatory retirement age) would they have a significant impact on the timing of aggregate net migration flows.

\section{Migration Data}

The migration data analyzed in this study were annual levels of net migration of the elderly into three rapidly growing states. Net migration is the difference between the number of persons moving into an area and the number moving out. The elderly population is defined as all persons age 65 and above. Annual estimates of the elderly population were derived from Medicare data. The Medicare program was established in 1965 to provide hospital and medical assistance to the elderly (age 65 and above) and disabled (less than age 65). The data used in this study refer only to elderly enrollees, or those 65 and above. At the state level, coverage of older persons by the Medicare program is very high and the correlation between Medicare enrollees and persons age 65 and above enumerated in the decennial census is extremely close (U.S. Bureau of the Census, 1976; Irwin, 1978; Hatten, 1980). Medicare data thus provide very reliable state estimates of the number of persons age 65 and above. ${ }^{3}$

Medicare data have been available every year since 1966. During the first several years of operation, however, coverage by the Medicare program was not universal. Changes in the number of enrollees included increases in the proportion of eligible persons enrolled as well as changes due to death, migration and persons reaching age 65 . By 1970 , coverage was virtually complete. To ensure the quality of the data used in this study, 1970 is the first year used in the empirical analysis.

Net migration of the elderly (MIG) was estimated as follows:

$$
\text { 2) } \mathrm{MIG}_{0}^{1}=\mathrm{POP}_{1}-\mathrm{POP}_{0}-\mathrm{NI}_{0}^{1}
$$

where: $\mathrm{MIG}_{0}^{1}=$ net migration of the elderly between times 0 and 1

$\mathrm{POP}_{1}=$ Medicare enrollees at time $1 * \mathbf{k}_{1}$

$\mathrm{POP}_{0}=$ Medicare enrollees at time

$\mathrm{NI}^{1}$ = natural increase of the elderly population between times 0 and 1

k = adjustment factor

While coverage by the Medicare program is generally quite good, there is rarely a perfect one-to-one relationship between Medicare enrollees and the population age 65 and above enumerated in the decennial census. Differences may arise because of incomplete coverage by the Medicare program, census undercount or overcount, data errors, differences in the dates for which data are collected, and differences in the ways in which residence is defined. The adjustment factor $\mathbf{k}$ was developed to account for these differences. The value of $k$ for 1970 and 1980 was computed by dividing the census-enumerated population age 65 and above by the number of Medicare enrollees for the same year (interpolated to April 1). For the years between 1970 and 1980 , the value of $\mathbf{k}$ was determined by a linear interpolation between the 1970 and 1980 values. Annual values of $\mathbf{k}$ for the states covered by this study are shown in the appendix.

The natural increase of the elderly population cannot be calculated directly because single year age data are not available for all states for inter-censal years. It can be estimated, however, from national Medicare data. The increase in Medicare enrollees for the United States can be used as an estimate of the natural increase of the national elderly population because international migration has a very small impact on the annual increase in the elderly population. In this study, we assume that the rate of natural increase of the elderly population is the same for each state as for the nation as a whole. The annual percentage change in the number of Medicare enrollees nationally is multiplied by the elderly population 
Table 1

Net Migration of the Elderly, 1970-1980

\begin{tabular}{ccccccc}
\hline \hline Year & Florida & Arizona & Nevada & New York & Illinois & Massachusetts \\
\hline 1970 & 38,372 & 6,748 & 1404 & $-18,762$ & $-9,213$ & -7281 \\
1971 & $\mathbf{4 7 , 7 2 2}$ & 8,464 & 1676 & $-25,540$ & $-8,531$ & -7401 \\
1972 & 49,175 & 8,683 & 1782 & $-25,515$ & $-9,125$ & -5479 \\
1973 & 50,497 & 9,433 & 1833 & $-29,193$ & $-11,374$ & -5243 \\
1974 & 50,896 & 8,460 & 2202 & $-22,964$ & $-9,777$ & -5517 \\
1975 & 28,831 & 7,956 & 1929 & $-14,933$ & $-7,940$ & -5132 \\
1976 & 29,693 & 9,146 & 2438 & $-23,448$ & $-5,359$ & -7782 \\
1977 & 33,139 & 11,469 & 3071 & $-28,069$ & $-8,974$ & -4785 \\
1978 & 47,283 & 13,061 & 3618 & $-28,245$ & $-11,394$ & -4865 \\
1979 & 42,595 & 11,284 & 3369 & $-26,669$ & $-9,274$ & -4876 \\
1980 & 27,006 & 9,584 & 3777 & $-23,802$ & $-8,788$ & -5044 \\
\hline \hline
\end{tabular}

of each state to provide an estimate of the natural increase of the elderly population for states. ${ }^{4}$

Ideally, a time series study of elderly migration would analyze gross in- and out-migration data separately. Unfortunately, such data are not available on an annual basis. For areas that are persistent net importers of elderly migrants, however, the effects of the explanatory variables are expected to be the same for net migration as for gross migration. If the number of in-migrants is persistently greater than the number of out-migrants, the same factors that promote gross in-migration also promote net in-migration. It is therefore possible to test the hypotheses of the theoretical model even though the migration data refer to net rather than gross flows.

\section{Empirical Analysis}

The model of migration of the elderly into attractive areas was tested using net migration data for three states: Florida, Arizona and Nevada. These states had the largest percentage increases in the elderly population of any mainland state between 1970 and 1980. Coincidentally, they are representative of a large state (Florida), a middle-sized state (Arizona) and a small state (Nevada), providing applications of the model to states with considerably different levels of absolute migration flows. Annual levels of net migration of the elderly between 1970 and 1980 for these states are shown in Table 1. (Table 1 also provides data for three other states, which will be discussed later in this article.)

A lag structure must be specified before the model can be applied. Lagged relationships between the explanatory variables and net migration are expected for two reasons. First, there are delays in the flow of information. Migration decisions may be based on perceptions of the rate of inflation or the condition of the housing market from an earlier time period. Second, carrying out a decision to move requires preparation: selling a house, finding a new place to live, and arranging for transportation all take a good deal of time. In this study, both explanatory variables were lagged one year.

Equation 1 was set in linear form and ordinary least square (OLS) regression analysis was applied using annual data from 1970 through 1980. The results are shown in Table 2. Sales of existing single family housing units (HOUSE) is expressed in hundreds of thousands of units, and inflation (INFL) is expressed as the price index for consumer expenditures (base $1972=100$ ). In all three states, the fit of the equation was quite good, as indicated by

Table 2

OLS Regression Results for Florida, Arizona and Nevada*

\begin{tabular}{|c|c|c|c|c|c|c|}
\hline State & Intercept & HOUSE & INFL & Adj. R2 & F & DW \\
\hline Florida & $\begin{array}{r}96,006 \\
(9.91)\end{array}$ & $\begin{array}{l}2961 \\
(4.92)\end{array}$ & $\begin{array}{l}-1117 \\
(-5.67)\end{array}$ & .768 & 17.53 & 2.72 \\
\hline Arizona & $\begin{array}{c}7,882 \\
(3.44)\end{array}$ & $\begin{array}{c}388 \\
(2.72)\end{array}$ & $\begin{array}{r}-72 \\
(-1.54)\end{array}$ & .650 & 10.27 & 1.43 \\
\hline Nevada & $\begin{array}{c}-757 \\
(-1.67)\end{array}$ & $\begin{array}{c}63 \\
(2.25)\end{array}$ & $\begin{array}{c}13 \\
(1.44)\end{array}$ & .938 & 77.00 & 2.46 \\
\hline
\end{tabular}


the large adjusted $R^{2}$ and F-statistic. As expected, HOUSE had a significant positive effect on net migration of the elderly into all three states. INFL, however, had the expected negative sign only for Florida and Arizona and was significant only for Florida.

One of our hypotheses was strongly supported: a strong housing market in which large numbers of existing single family houses are being sold has a significant positive effect on net migration of the elderly into attractive areas. Other things being equal, more elderly persons will move into these states during years when single family houses are relatively easy to sell than during years when they are relatively hard to sell. The second hypothesis was only marginally supported, however. The rate of inflation had the expected negative effect on two out of three states, but was significant only in one.

While these results are fairly good, they tell only part of the story. One objective of the present study is to provide the basis for improving short-run forecasts of the elderly population. A universally accepted set of criteria for assessing forecasting accuracy does not exist, but some guidelines can be found in the literature (e.g. Drhymes, et al, 1972). Three tests are often suggested:

1) tracking within the sample period,

2) behavior at turning points, and

3) tracking outside the sample period

The present model performs quite well on each of these tests. Tracking within and outside the sample period is measured by the root mean squared percentage error (RMSPE), defined as:

$$
\text { 3) } \mathrm{RMSPE}=\left[\begin{array}{l}
1 \mathrm{~N} \\
-\sum_{\mathrm{i}=1}
\end{array}\left(\frac{\mathrm{A}_{\mathrm{i}}-\mathrm{P}_{\mathrm{i}}}{\mathrm{A}_{\mathrm{i}}}\right)^{2}\right]^{1 / 2}
$$

where: $\mathbf{A}_{\mathbf{i}}=$ actual net migration during year $i$ and

$\mathbf{P}_{\mathbf{i}}=$ predicted net migration during year $i$.

Within the sample period 1970 through 1980, the RMSPE was 10.2 for Florida, 9.5 for Arizona and 7.5 for Nevada. These relatively small errors show that the levels of net migration predicted by the model fit quite closely with those observed over the sample period. Figure 1 shows graphically the closeness of this fit.

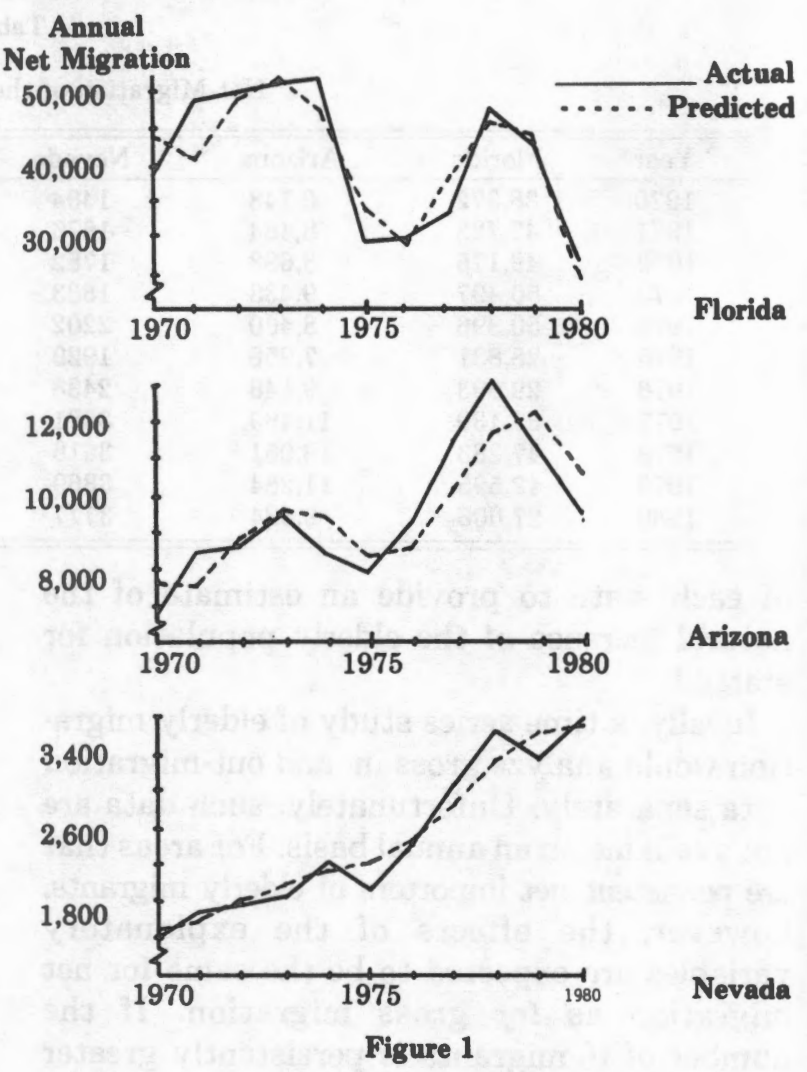

Actual and Predicted In-Sample Levels of Elderly Net Migration for Florida, Arizona and Nevada: 1970-1980

The model also performed reasonably well in capturing major turning points. In Florida and Arizona, there were three major turning points between 1970 and 1980. The model predicted one of these exactly and missed the other two by only one year. In Nevada, there were no major turning points, although there were two small downturns followed immediately by substantial upturns the following year. The model did not predict either of these small downturns, but did show smaller upturns in those years. As can be seen in Figure 1, the model's simulation of net migration trends followed quite closely the actual migration trends in all three states.

The final test covers tracking outside the sample period. This is, perhaps, the toughest test to which a model can be subjected. The model's coefficients were re-estimated for each state using data from 1970 to 1977. Forecasts for 1978 through 1980 were then produced from the resulting regression coefficients. Figure 2 shows the actual and predicted net migration levels outside the sample period for each state.

In Florida, the large downturn between 1978 and 1980 was correctly predicted, although the magnitude of the decline was overstated. The RMSPE was 18.8. In Arizona, the downturn 
was predicted a year too late and the magnitude was understated. The RMSPE was
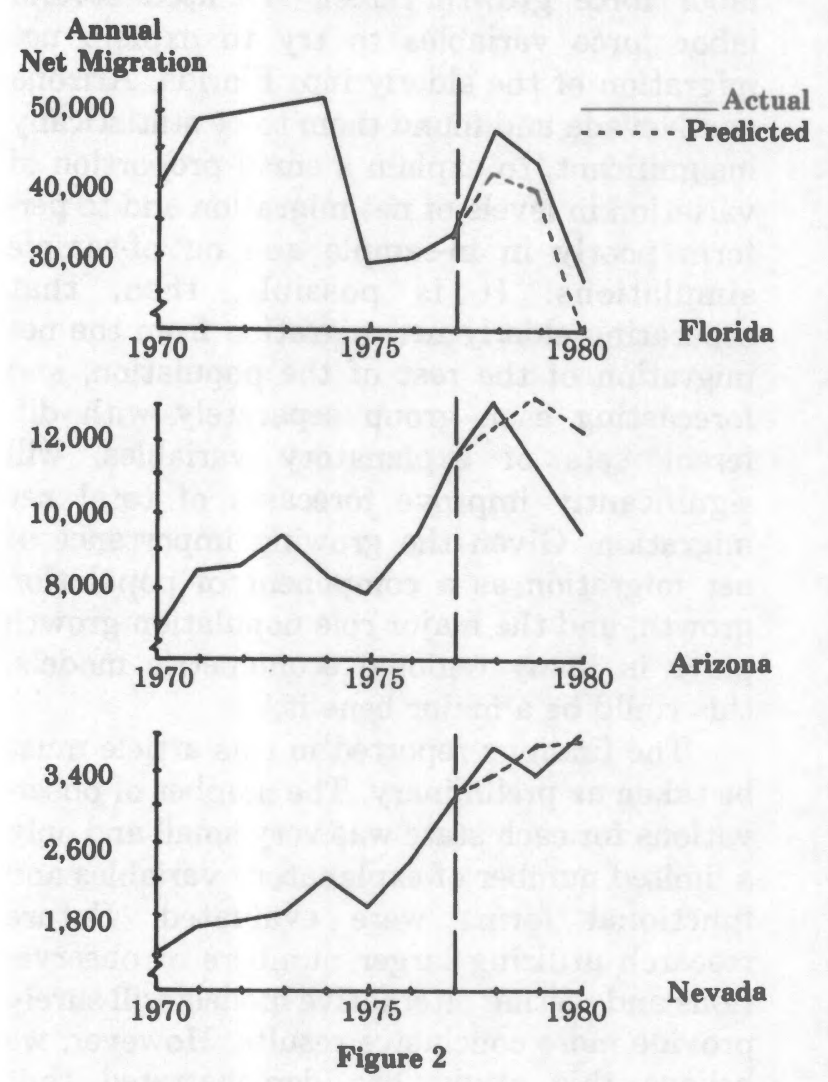

Actual and Predicted Out-of-Sample Levels of Elderly Net Migration for Florida, Arizona and Nevada: 1978-1980

19.0. In Nevada, a slight downturn occurred in 1979 that was not predicted by the model. However, the errors in all three years were very small, as indicated by the RMSPE of only 7.0. The model thus correctly predicted the general shape of net migration trends outside the sample period in all three states: a huge decline in Florida, a moderate decline in Arizona and a continued increase in Nevada. Given the large differences among these three states, that is quite a good job of out-of-sample forecasting.

The model performed well in explaining and forecasting the timing of net migration of the elderly into three rapidly growing states. How would it work for a region with a net outflow of elderly migrants? The theoretical model implies that factors having positive effects on net migration of the elderly into attractive areas should have negative effects for unattractive areas, and vice versa. To test this hypothesis, we ran the model using annual levels of net migration of the elderly for New York, Illinois and Massachusetts, the three states with the smallest percentage increases in elderly population between 1970 and 1980. Each of these states had negative net migration of the elderly during every year of the $1970 \mathrm{~s}$, as shown in Table 1. For New York and Illinois, the results of the analysis were as expected: HOUSE had a significant negative effect on net migration of the elderly and INFL a significant positive effect. The model tracked well within the sample period and predicted the turn-around in trends that occurred outside the sample period. For Massachusetts, however, the results were poor, as both explanatory variables had the wrong sign. Complete results for these three states are available from the authors upon request.

\section{Summary and Conclusions}

A great deal of attention in recent years has been given to the migration behavior of older persons. Origins, destinations, labor force status, level and source of income, educational background, health, marital status and type of housing are among the topics that have been covered. In spite of this large amount of research, no study has focused on the timing of elderly migration, or tried to explain why flows of elderly migrants into many states and local areas are larger some years than other years. In this article, we developed a model of changes in levels of elderly migration over time. This model was able to explain a large proportion of the variation in annual levels of net migration of the elderly into three rapidly growing states and produced in- and out-ofsample simulations of net migration that tracked very well with the levels of net migration actually observed. The model also performed well in an application to two of three states undergoing persistent net out-migration of the elderly. Although the large majority of elderly interstate migrants are not in the labor force, the timing of their migration decisions is strongly affected by changing economic conditions (particularly those affecting the housing market).

Many refinements and extensions to this model could be made. We used national data for the explanatory variables; data at the state level could also be used, focusing on differences among states in prices of consumer goods, housing, tax burdens or quality of life indicators. Different explanatory variables could be tried, such as mortgage rates, housing prices or other price and income effects directly affecting older persons (e.g. costs of health care). The effects of noneconomic variables 
that fluctuate over time could be explored. Applications to metropolitan areas or other substate regions could be made. ${ }^{5}$ This study has shown that large temporal variations in levels of elderly migration do occur, and that these variations can be partially explained by changing economic conditions. The potential is great for additional research into the causes of these variations.

We believe the present and similar models can be usefully applied to rapidly growing areas. It is also quite possible that useful models can be developed for areas with a net outflow of elderly migrants: factors that promote migration into rapidly growing areas, at the same time promote migration out of slowly growing or declining areas. We found our model to work well in two or three states undergoing persistent net out-migration of the elderly. The applicability of the model to areas experiencing neither persistent net inflows nor persistent net outflows is questionable, however. If net migration of the elderly is positive during some years and negative during others, the national-level explanatory variables used in this study will not be able to provide a rational explanation of fluctuations over time. In such circumstances, explanatory variables at the state or regional level would have to be explored.

A study of the timing of elderly migration is useful not only by adding to our understanding of the migration process, but also by improving our ability to forecast short-run changes in the elderly population. The explanatory variables in the present model affected net migration of the elderly only after a lag of one year. These variables themselves can be forecast in the short run with some degree of accuracy. Forecasts of elderly migration can therefore be used with forecasts of the natural increase of the elderly population to make short-run forecasts of the total elderly population. As the elderly populations of states and local areas increase both in numbers and as proportions of total population, accurate forecasts of the elderly population become increasingly important for public and private sector decision-making. ${ }^{6}$

The capability to produce short-run forecasts of the elderly population may improve shortrun forecasts of total population as well. Net migration of the elderly is not likely to be significantly affected by the labor force variables typically found in time series models of total net migration or total population change (e.g. unemployment rates, wage rates, labor force growth rates). We used several labor force variables to try to explain net migration of the elderly into Florida, Arizona and Nevada and found them to be statistically insignificant, to explain a small proportion of variation in levels of net migration and to perform poorly in in-sample and out-of-sample simulations. It is possible, then, that separating elderly net migration from the net migration of the rest of the population, and forecasting each group separately with different sets of explanatory variables, will significantly improve forecasts of total net migration. Given the growing importance of net migration as a component of population growth, and the major role population growth plays in many regional econometric models, this could be a major benefit.

The findings reported in this article must be taken as preliminary. The number of observations for each state was very small and only a limited number of explanatory variables and functional forms were evaluated. Future research utilizing larger numbers of observations and testing alternative models will surely provide more conclusive results. However, we believe this study has demonstrated that substantial temporal variations in levels of elderly migration do exist, and that models can be developed to explain past variations and predict future variations. Further research on this neglected aspect of elderly migration behavior promises to add to our understanding of the migration process, and to improve the accuracy of short-run population forecasts as well.

\section{FOOTNOTES}

\footnotetext{
${ }^{1}$ Miller (1966, p. 59) reported that migrants aged 65 and above had an average labor force participation rate of $\mathbf{1 7 . 5}$ percent in 1960 . Goldstein $(1967$, p. 39$)$ reported that interstate migrants aged 65 and above had labor force participation rates of less than 10 percent in 1960 . Unpublished data from the 1970 census show that only 8.3 percent of the persons aged 65 and above who moved to Florida between 1965 and 1970 were in the labor force in 1970 .

${ }^{2}$ It is perhaps not surprising that real social security payments per capita had a small, generally insignificant effect on net migration of the elderly because payments changed relatively little in real terms over the time period covered by this study. In addition, social security payments decline as a proportion of income as income rises (Fox, 1973 p. 40). Since elderly interstate migrants tend to be positively selected by income (Barsby and Cox, 1975 , p. 16; Biggar, 1980, p. 178), social security payments are not as important a source of income for elderly interstate migrants as for the elderly population in general.

${ }^{3}$ One problem with Medicare data is that the number of
} 
enrollees refers to a date of July 1 while geographic residence coding includes address changes during a period of approximately nine months after the reference date. For example, the number of Medicare enrollees in the state of Florida reported for July 1,1980 is actually the number of people enrolled anywhere on July 1,1980, who claimed a Florida address in March, 1981. There is apparently no way to solve this problem, given the procedures currently followed in compiling the data (Irwin, 1978, p. 11). While this discrepancy has a small effect on estimates of the number of enrollees residing in any state on any given date, it has virtually no effect on estimates of annual changes in the number of enrollees. In this study we assume that July 1 data actually indicate residence the following January 1.

The natural increase of the elderly population may differ somewhat from state to state because of differences in age-specific mortality rates and the age structure of the older population. We believe these differences are small enough to make our assumption regarding natural increase quite reasonable. Although some differences may exist, they will most likely have an impact primarily on the levels of net migration rather than on the annual change in levels, which is the focus of this study.

"While Medicare data are available at the county and even zip code level, the correlation between Medicare enrollees and the population age 65 and above is typically not as high for counties and zip code areas as for states. Discrepancies between the two sources of data are particularly large for zip code areas and small counties. Time series models of net migration for substate areas will be most successful if they are confined to large metropolitan areas or groups of counties.

'We believe this and similar models can provide useful forecasts of the elderly population for up to three, four or possibly five years. Beyond such a time horizon changes in age structure began to affect migration levels and, more important, the validity of predicted values for the explanatory variables becomes quite dubious.

TThe econometric model of the state of Florida developed by the Bureau of Economic and Business Research at the University of Florida incorporates the separation of net migration into these two parts, each with its own estimating equation. Such a separation was found to improve the forecasting performance of the entire model.

\section{REFERENCES}

Bach, G. L. and James B. Stephenson (1974). "Inflation and the Redistribution of Wealth," Review of Economics and Statistics, Vol. 56, No. 1, pp. 1-13.

Barsby, Steve and Dennis Cox (1975). Interstate Migration of the Elderly, D. C. Heath, Lexington, Mass.

Bell, Frederick (1967). "An Econometric Forecasting Model for a Region," Journal of Regional Science, Vol. 7, No. 2, pp. 109-127.

Biggar, Jeanne (1980). "Reassessing Elderly Sunbelt Migration," Research on Aging, Vol. 2, No. 2, pp. 177-190.

Bultena, Gordon and Vivian Wood (1969). "Normative Attitudes Toward the Aged Role Among Migrant and Non-Migrant Retirees," The Gerontologist, Vol. 9, No. 3 , pp. 204-208.

Bowles, Samuel (1970). "Migration as Investment: Empirical Tests of the Human Investment Approach to Geographical Mobility," Review of Economics and Statistics, Vol. 52, No. 4, pp. 356-362.

Cebula, Richard and Richard Vedder (1973). "A Note on Migration, Economic Opportunity and the Quality of Life," Journal of Regional Science, Vol. 13, No. 2, pp. 205-211.
Chevan, Albert and Lucy Rose Fisher (1979). "Retirement and Interstate Migration," Social Forces, Vol. 75, No. 4, pp. 1365-1380.

Crow, Robert (1973). "A Nationally-Linked Regional Econometric Model," Journal of Regional Science, Vol. 13, No. 2, pp. 187-204.

Dhrymes, Phoebus, E. Phillip Howrey, Saul H. Hymans, Jan Kmenta, Edward E. Leamer, Richard E. Quandt, James B. Ramsey, Harold T. Shapiro and Victor Zarnowitz (1972). "Criteria for Evaluation of Econometric Models," Annals of Economic and Social Measurement, Vol. 1, No. 3, pp. 291-324.

Fields, Gary (1976). "Labor Force Migration, Unemployment and Job Turnover," Review of Economics and Statistics, Vol. 58, No. 4, pp. 407-415.

Flynn, Cynthia (1980). "General Versus Aged Interstate Migration, 1965-1970," Research on Aging. Vol. 2. No. 2, pp. $165-176$.

Fox, Alan (1973). "The Income of Newly Entitled Beneficiaries, 1970," Department of Health, Education and Welfare, Social Security Administration, Report No. 10, pp. 1-58.

Goldscheider, Calvin (1966). "Differential Residential Mobility of the Older Population," Journal of Gerontology, Vol. 21, No. 1, pp. 103-108.

Goldstein, Sidney (1967). "Socio-Economic and Migration Differentials Between the Aged in the Labor Force and in the Labor Reserve," The Gerontologist, Vol. 7, No. 1, pp. 31-41.

Graves, Philip and Peter Linneman (1979). "Household Migration: Theoretical and Empirical Results," Jour nal of Urban Economics, Vol. 6, No. 3, pp. 383-404.

Graves, Philip (1979). "A Life-Cycle Empirical Analysis of Migration and Climate, by Race," Journal of Urban Economics, Vol. 6, No. 2, pp. 135-147.

Hatten, James (1980). "Medicare's Common Denominator: The Covered Population," Health Care Financing Review, Fall, pp. 53-64.

Irwin, Richard (1978). "Aggregate Medicare Enrollment by Age, Sex and Race as a Resource in Analyzing Demographic Change for Local Areas," paper presented at NBER Workshop on Policy Analysis with Social Security Files, Williamsburg, VA.

Kau, James and C. F. Sirmans (1977). "The Influence of Information Cost and Uncertainty on Migration: A Comparison of Migrant Types," Journal of Regional Science, Vol. 17, No. 1, pp 89-96.

Lenzer, Anthony (1965). "Mobility Patterns Among the Aged, 1955-1960," The Gerontologist, Vol. 5, No. 1, pp. 12-15.

Levy, Mildred and Walter Wadycki (1972). "Lifetime Versus One-Year Migration in Venezuela," Journal of Regional Science, Vol. 12, No. 3, pp. 407-415.

Long, Larry and Kristin Hansen (1979). "Reasons for Interstate Migration," Current Population Reports, Series P-23 No. 81.

Manley, Charles (1954). "The Migration of Older People," American Journal of Sociology, Vol. 59, pp. 324-331.

Miller, Ann (1966). "Migration Differentials in Labor Force Participation: United States, 1960," Demography, Vol. 3, No. 1, pp. 58-67.

Milne, William (1981). "Migration in an Interregional Macroeconomic Model of the United States: Will Net Outmigration from the Northeast Continue?", Inter national Regional Science Review, Vol. 6, No. 1, pp. 77-83.

Plaut, Thomas (1981). "An Econometric Model for Forecasting Regional Population Growth," International Regional Science Review, Vol. 6, No. 1, pp. 53-70.

Salvatore, Dominick (1977). "An Econometric Analysis of Internal Migration in Italy," Journal of Regional 
Science, Vol. 17, No. 1, pp. 395-408.

Serow, William (1978). "Return Migration of the Elderly in the U.S.A.: 1955-1960 and 1965-1970," Journal of Gerontology, Vol. 33, No. 2, pp. 288-295.

Sherman, Sally R. (1973). "Assets on the Threshold of Retirement," Social Security Bulletin, Vol. 36, No. 8, pp. 3-17.

Sjaastad, Larry (1962). "The Costs and Returns of Human Migration," Journal of Political Economy, Vol. 70, No. 5, Part 2, pp. 80-93.

Social Security Administration (1980). "Income and
Resources of the Aged," SSA Publication No. 1311727, January.

Wentworth, Edna and Dena Motley (1970). "Resources After Retirement," Department of Health, Education and Welfare, Social Security Administration, Research Report No. 34, pp. 1-69.

Wilkinson, Maurice (1970). "European Migration to the United States: An Econometric Analysis of Aggregate Labor Supply and Demand," Review of Economics and Statistics, Vol. 52, pp. 272-279.

\section{Appendix}

Adjustment factor (k) for states, 1970-1980

\begin{tabular}{ccccccc}
\hline \hline Year & Florida & Arizona & Nevada & New York & Illinois & Massachusetts \\
\hline 1970 & 1.0712 & 1.0291 & .9907 & .9969 & .9959 & 1.0019 \\
1971 & 1.0718 & 1.0317 & .9949 & .9990 & .9986 & 1.0037 \\
1972 & 1.0724 & 1.0343 & .9991 & 1.0011 & 1.0013 & 1.0055 \\
1973 & 1.0730 & 1.0370 & 1.0033 & 1.0031 & 1.0040 & 1.0074 \\
1974 & 1.0736 & 1.0396 & 1.0075 & 1.0052 & 1.0067 & 1.0092 \\
1975 & 1.0742 & 1.0422 & 1.0116 & 1.0073 & 1.0094 & 1.0110 \\
1976 & 1.0748 & 1.0448 & 1.0158 & 1.0094 & 1.0121 & 1.0128 \\
1977 & 1.0754 & 1.0474 & 1.0200 & 1.0115 & 1.0148 & 1.0146 \\
1978 & 1.0760 & 1.0501 & 1.0242 & 1.0135 & 1.0175 & 1.0165 \\
1979 & 1.0766 & 1.0527 & 1.0284 & 1.0156 & 1.0201 & 1.0183 \\
1980 & 1.0772 & 1.0553 & 1.0326 & 1.0177 & 1.0229 & 1.0201 \\
\hline \hline
\end{tabular}

